Int. J. Electrochem. Sci., 14 (2019) 9380 - 9390

\title{
Determination of Epinephrine using a Novel Sensitive Electrochemiluminescence Sensor based on ZnO Nanoparticles Modified Pencil Graphite Electrode
}

\author{
Ruijuan Zheng ${ }^{1}$, Chenhao Zhao ${ }^{1}$, Jianhai Zhong ${ }^{2}$,Zehai Qiu ${ }^{1, *}$, Zhibiao Hu ${ }^{1, *}$ \\ ${ }^{1}$ College of Chemistry and Materials, Longyan University, Longyan, Fujian, China, 364012. \\ ${ }^{2}$ Longyan customs, Longyan, Fujian, China, 364012 \\ *E-mail: 814971361@qq.com, zhibiaohu@163.com
}

doi: $10.20964 / 2019.09 .51$

Received: 7 May 2019 / Accepted: 4 July 2019 / Published: 5 August 2019

The accurate determination of epinephrine is important for medical application. In the paper, a novel electrochemiluminescence (ECL) sensor, $\mathrm{ZnO}$ nanoparticles modified pencil graphite electrode (ZnO/PGE) was fabricated by self-prepared $\mathrm{ZnO}$ and low-cost $2 \mathrm{~B}$ pencil graphite. The $\mathrm{ZnO} / \mathrm{PGEs}$ showed excellent electrochemiluminescence performances and the possible electrochemiluminescence mechanism of $\mathrm{ZnO} / \mathrm{PGEs}$ was also discussed. The effects of experimental parameters such as scanning rate, $\mathrm{pH}$, concentrations of persulfate and reproducibility on ECL intensity have been investigated. Under the optimum condition, the ECL intensity of $\mathrm{ZnO} / \mathrm{PGE}$ decreased linearly with concentrations of epinephrine over the wide range from $8 \times 10^{-10}$ to $2 \times 10^{-7} \mathrm{~mol} \mathrm{~L}{ }^{-1}$, with detection limit of $1 \times 10^{-10} \mathrm{~mol} \mathrm{~L}^{-1}$ $(\mathrm{S} / \mathrm{N}=3)$. The results showed that this novel sensor was successfully applied for the analysis of epinephrine in drug samples with satisfactory results.

Keywords: Pencil graphite electrode, $\mathrm{ZnO}$, Electrochemiluminescence, Epinephrine

\section{FULL TEXT}

(C) 2019 The Authors. Published by ESG (www.electrochemsci.org). This article is an open access article distributed under the terms and conditions of the Creative Commons Attribution license (http://creativecommons.org/licenses/by/4.0/). 